\title{
A Comparative Study on the Effect of Qi -Lu Cultural Differences on Regional Economic Development in Shandong
}

\author{
Jinqing Zhang \\ Shandong Management University, Jinan, Shandong 250357
}

Keywords: Qi-Lu culture; regional economy; cultural powerhouse

\begin{abstract}
There is a close correlation between culture and economy, and economic development of any region is inseparable from cultural factors. Qi-Lu culture, as one of the traditional Chinese cultures, exerts a profound impact on economic development of Shandong. This paper analyzes the similarities and differences between Qi culture and Lu culture, and takes economic development of Jining and Zibo as examples to investigate the characteristics of regional economic development in Shandong Province under the impact of the two cultures. Regional economic development is inseparable from driving force of culture. Traditional culture not only needs to be promoted, but moreover, reformed and innovated. Only in this way can we promote the construction of Shangdong as a strong economic and cultural powerhouse.
\end{abstract}

Culture means a tradition. It is under combined action of factors like a region's unique geographical environment, natural conditions, customs, humanities, history, politics that the region's unique culture is formed[1]. Economy is formed on certain cultural basis. The development of regional economy is inseparable from the driving force of regional culture. In turn, the economy acts on the inheritance and development of culture[2]. The integrated development of culture and economy can not only provide a source of power for economic development, but also carry forward the promotion and prosperity of culture.

\section{The Status Quo of Regional Economic Development in the East and West of Shandong Province}

\subsection{Shandong Province features good economic development in overall}

Since 2007, Shandong Province has been ranking third in the country in terms of economic aggregates, which is one of the provinces with rapid development rate in the country. In 2008, Shandong's GDP reached 3107.21 billion yuan, accounting for about 9.7\% of the country's total GDP, and its per capita GDP was 33083 yuan. In 2018, Shandong's GDP reached 7,646.97 billion yuan, accounting for about $8.5 \%$ of the country's total GDP. The ranking was second only to Guangdong and Jiangsu, with a per capita GDP of 76267 yuan. Figure 1 reveals that, since 2008, the province's GDP and annual growth rate demonstrate steady growth.

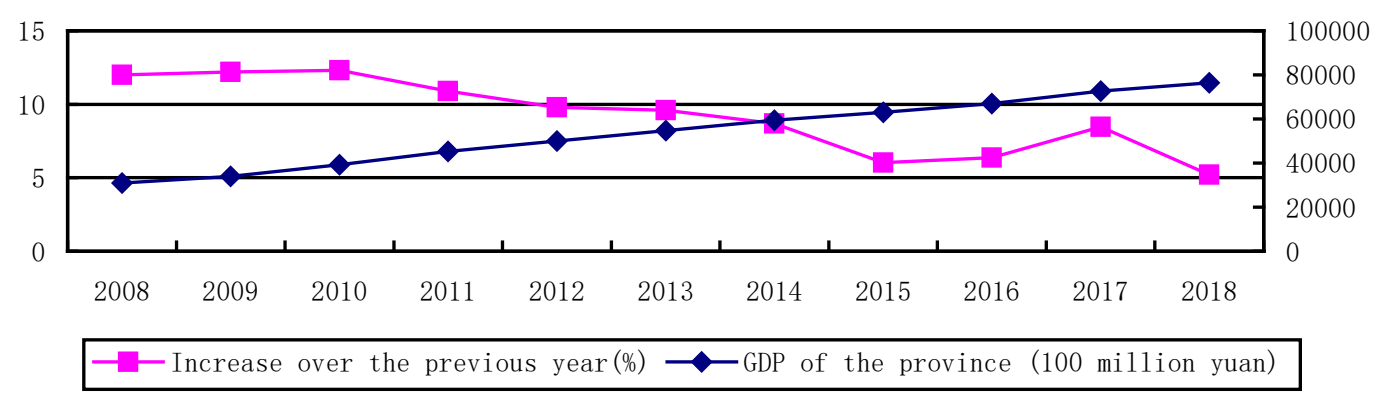

Figure 1 Shandong Province's GDP and Average Annual Growth Rate from 2008 to 2018

Source: Compilation and calculation based on data from Shandong Statistical Information Network 


\subsection{There are obvious differences in economic development between the eastern and western regions, showing an uneven growth trend}

Affected by factors such as nature, history and economic foundation, economic development of various cities in Shandong Province exhibits obvious regional differences. Although the trend of widening gaps has slowed in recent years, there is still a big gap in per capita economic indicators between the regions[3]. For regional division of Shandong, there are a variety of views in the academic community. The generally accepted method is to classify Jinan, Qingdao, Zibo, Yantai, Weifang, Weihai, Dongying, Tai'an, Rizhao and Binzhou as the eastern region (in further subdivision, Jinan, Zibo, Tai'an, Binzhou, Dongying can be classified as the central region), while Dezhou, Liaocheng, Jining, Zaozhuang, Linyi and Heze are collectively referred to as the western region. Some scholars include Tai'an and Binzhou in the western region based on per capita income indicators and industrial structure indicators. The first division method is adopted herein. In general, compared with the more developed eastern regions, the western region has relatively backward economic development with obvious gap. Such gap will inevitably exert a negative impact on the coordinated development of Shandong Province.

\section{Analysis on Qi and Lu Cultural Factors Affecting the Eastern and Western Economic Development of Shandong Province}

Qi culture and Lu culture means the total material and non-material cultures created and accumulated by the ancestors of Qi and Lu over long-term social practice. As the two traditional cultures in Shandong, they are both the main source and important part of Chinese traditional culture. The inclusive and open-minded Qi culture not only develops Qi people's utilitarianism that values material interests, but also cultivates Qi people's pioneering spirit of change. Confucian culture constitutes the core of Lu culture, which governs China as an orthodox culture in feudal society for more than two thousand years. It can be said that its influence spreads all over the world[4].The two cultures form the backbone of traditional Chinese culture together.

\subsection{Viewing Qi Culture and Lu Culture from Cultural Origin}

Both Qi culture and Lu culture belong to the Dongyi cultural circle. As far as Qi and Lu are concerned, Dongyi people of Qi area lived in the coastal and peninsular areas and developed fishing and hunting-based coastal peninsula culture over the long years. Dongyi people of Lu area lived in Wen, Si River Basin and developed an inland river valley culture with agriculture as its main production. Qi and $\mathrm{Lu}$ states adopted different political strategies, thus further increasing the differences in cultural origin. Qi culture inherits the advanced factors of Dongyi culture, thereby exhibiting strong color of Dongyi culture. Lu culture, on the other hand, highlights the characteristics of inland agricultural culture and greatly dilutes the color of Dongyi culture.

\subsection{Comparison of Qi Culture and Lu Culture from Governance of Qi and Lu}

As the vassal states of the Zhou Kingdom, Qi and Lu states are inevitably affected by rites of Zhou. In respect of Zhou rites, Lu state is even more earnest, regarding rites and music as political tools of governance. From the perspective of staffing, Qi state is different from Lu state in that it has always adhered to the strategy of "respecting virtue and honoring merits" and made it an important staffing system in Qi state for promotion, which greatly promoted Qi state's prosperity. Compared with Qi state, Lu state adhered to the principle of "being respectful and harmonious" and firmly believed that "those who are not our kin are sure to have a different heart", which made it difficult for virtuous people to enter the political power center of Lu state. Following Zhou rites and discouraging emancipation of minds, the ruling circle of Lu state lacked vitality and energy.

\subsection{Different effects of Qi culture and Lu culture on economic development}

Both Qi state and Lu state paid great attention to agricultural development in terms of economic development. Located in the inland, Lu state had prosperous farming. Adhering to the policy of stressing agriculture and restraining commerce, it attached importance to the cultivation of grains 
and mulberry, but ignored the development of advantageous forestry and commerce, so commodity economy was very underdeveloped. Working from dawn to dusk, Lu people were content with self-sufficient natural economy, which seriously affected the development of Lu state. Since 594 $\mathrm{BC}$, Lu state implemented an agricultural land tax system that levied taxes as per mu, thus recognizing the legalization of land privatization, and gradually transitioning to feudal society first. Located in the coastal peninsula, Qi state had a thin land and sparse population. It not only attached importance to agricultural development and production technology transformation, but also valued fishing, salt, and commerce. Implementing the policy with "equal emphasis on agriculture and industry" under the call of "opening handicraft industry and commerce, tapping the potential of fishery and salt industry", the society was open with more developed commodity economy, and businessmen came and went in endless stream. By emphasizing and developing commerce, Linzi, the capital city of Qi state, finally became a metropolis in the east. With rich people and strong country, Qi state became a big oriental country with rich fishery and salt production. Conversely, Lu state simply relied on grains and mulberry, merely pursuing agricultural economic development, thus eventually failing to develop into a great power of vassal states.

\subsection{Sharp contrast between the openness of Qi culture and closeness of Lu culture}

In the process of cultural development and integration, Qi culture always adheres to the principle of attaching importance to its own survival and development needs. Good at merging and absorbing other cultures while maintaining its own cultural characteristics, it has formed a tradition of stressing strategies, valuing Kung $\mathrm{Fu}$, emphasizing utilitarianism, excelling at financial management and economic development. The openness of Qi culture has attracted many scholars to Jixia Academy to give lectures freely, cultivating Jixia scholars' strong sense of social responsibility, firm personality, open mind and fearless curious spirit. Confucianism-based Lu culture represents a closed inland agricultural culture of Zhou $\mathrm{Lu}$ on the basis of single agriculture. In the culture respecting rites and Confucianism, the people were niggard and observant of convention, feared and avoided evil, forming a simple folk custom [5-13].

\section{A Comparative Analysis on the Effect of Qi- Lu Cultural Differences on Regional Economic Development -Taking Jining and Zibo as Examples}

One country's soil and water breeds its culture, and its culture affects its economy. The Qi-Lu cultural differences have led to significant differences in ideology between Qi people and Lu people, which in turn leads to different characteristics of economic development in different regions, showing relative superiority and inferiority in economy. To date, the economic development of Shandong Province is still imbalanced between the eastern and western regions, and the western region has always lagged behind the eastern region in economic development, which is closely related to the region's adherence to Lu culture and lack of transforming spirit and innovation sense.

The author compares the current economic data of Zibo and Jining, where the capital cities of Qi and Lu states in Western Zhou Dynasty were located, and tries to analyze the different impacts of different cultures on regional economic development, thus further finding out the relationship between economy and culture to provide a new support for the implementation of the strategy of cultural powerhouse in Shandong.

\subsection{Effect of Lu Culture on the Economic Development of Western Shandong: A Case Study of Jining}

\subsubsection{Development Status of Jining City under the Effect of Lu Culture}

Located in the southwest of Shandong Province, Jining is the hometown of Confucius and Mencius as well as the capital of the Canal. As one of the important birthplaces of Oriental civilization and Chinese civilization, it has a total area of 11,187 square kilometers. According to the sixth census data at the end of 2018, it had a total population of 8.346 million, of which 3.34 million were rural and 4.912 million were urban. In 2018, the total GDP of Jining was 493.06 
billion yuan and the per capita GNP was 59078 yuan, ranking 12th among the province's 16 cities.

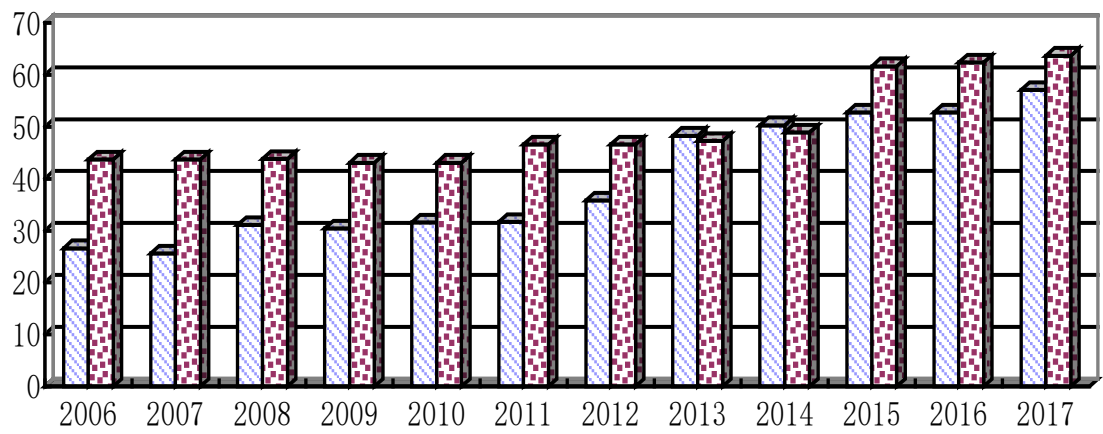

Figure 2 Changes in the proportion of urban population in Jining and Zibo cities since 2006 (\%)

Source: Compilation and calculation based on data from Shandong Statistical Information Network.

\subsubsection{Jining has slow speed of urbanization}

The level of urbanization can be taken as an important indicator for measuring the economic development level of a country or region. Internationally, the level of urbanization in a country or region is usually measured by urbanization rate. According to relevant regulations, urbanization rate = urban population / total population (both calculated based on permanent population). As can be seen from Figure 2, the proportion of urban population in the total population has been low in Jining City in recent years, which reflects the slow development of urbanization in Jining City to a certain extent. Such phenomenon is inseparable from the thought of stressing agriculture while restraining commerce in Lu culture. On the whole, urbanization level of Jining City shows obvious regional differences. The population density is higher than the provincial average with uneven spatial distribution. The urban construction level is in the middle of the province. With low town development level, the urban system development lags behind in overall.

\subsubsection{Jining City is relatively backward in industrial development}

From Figure 3, it can be seen that in the regional GDP of Jining, the absolute value added of the secondary industry is relatively high; but it can be seen from Figure 5 that compared to Zibo, the proportion of primary industry output value of Jining is not low in the regional GDP, which is higher than that of Zibo by nearly 9 percentage points, while the proportion of the secondary and tertiary industries is lower than that of Zibo.

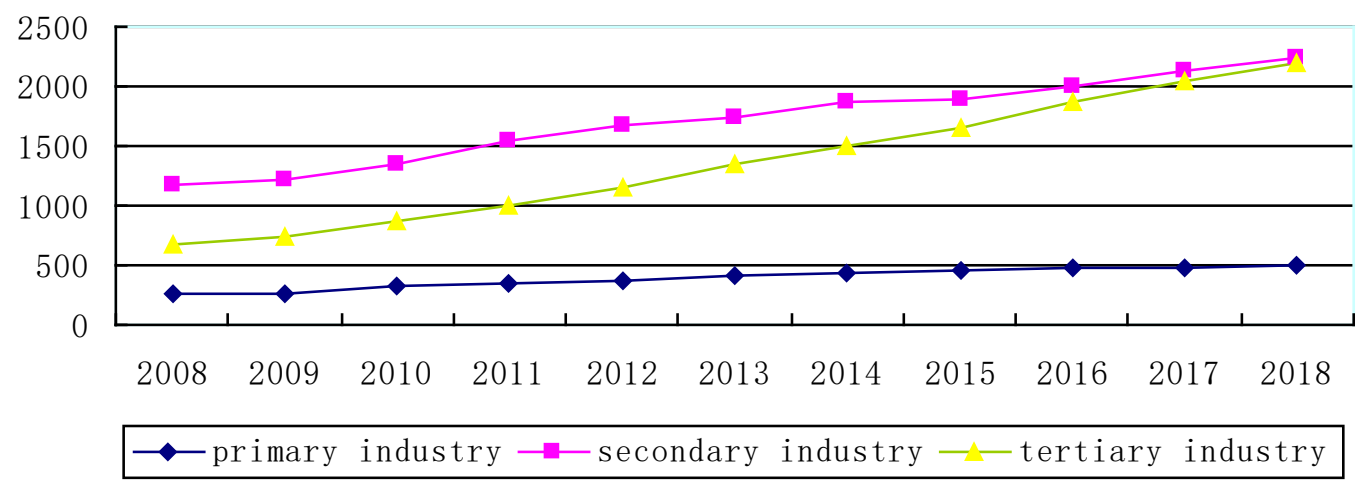

Figure 3 Value added of different industries in Jining during 2008-2018 (100 million yuan)

Source: Compilation and calculation based on data from Shandong Statistical Information Network 


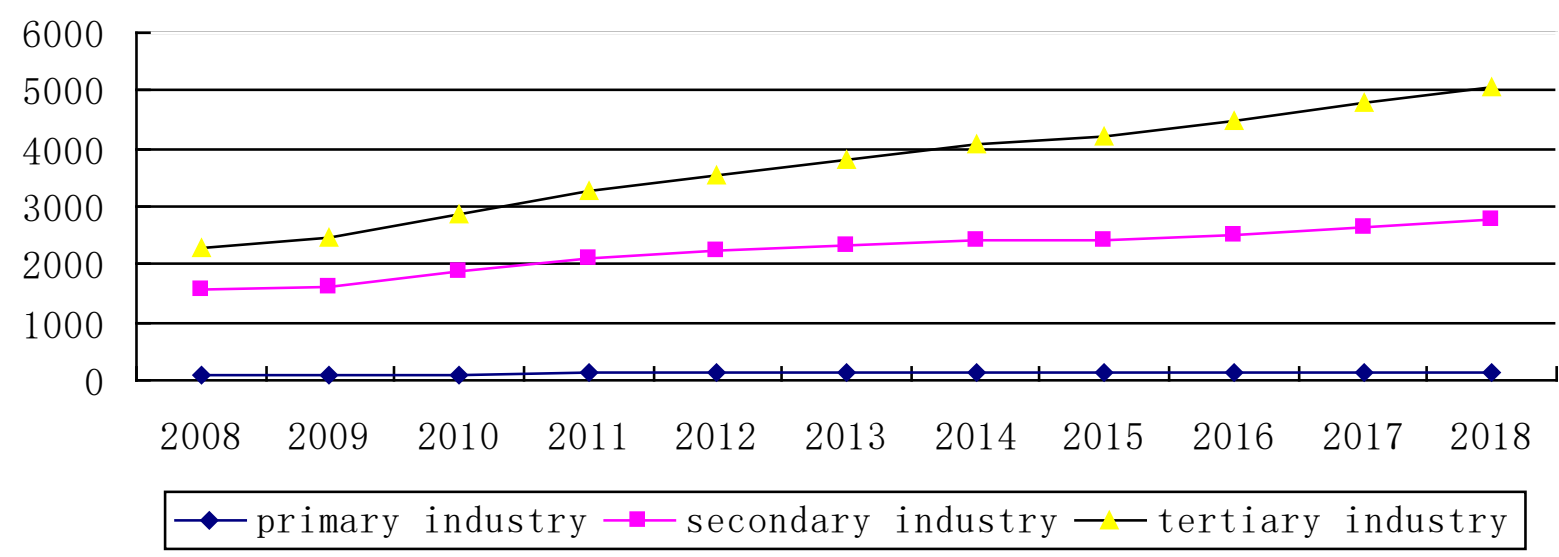

Figure 4 Value added of different industries in Zibo City during 2008-2018 (100 million yuan)

Source: Compilation and calculation based on data from Shandong Statistical Information Network

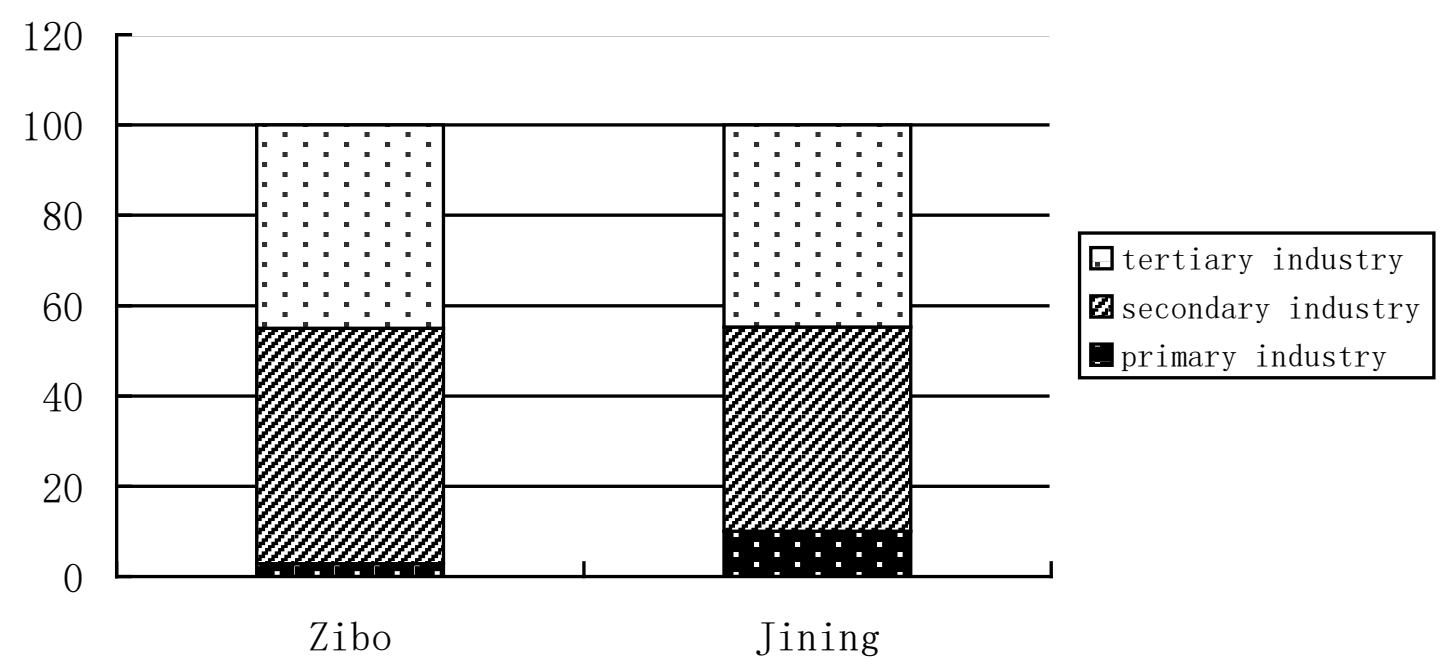

Figure 5 Comparison of the proportion of primary, secondary and tertiary industries (\%) in Jining and Zibo in 2018

Source: Compilation and calculation based on data from Shandong Statistical Information Network

\subsubsection{Jining's export-oriented economic development needs urgent improvement}

Due to the in-depth influence of Lu culture, Jining's export-oriented economic development relatively lags behind. An indicator for examining the development degree of export-oriented economy in a country or region is usually foreign trade dependence. Foreign trade dependence (foreign trade coefficient) refers to the ratio of the total import and export of a country or region to the GDP or GNP of the region. It reflects the degree of dependence of a country or region on international trade, as well as the degree of dependence of the country's or regional economic growth on import and export trade. Changes in the proportion indicate a change in the position of foreign trade in the national economy. Figure 6 reveals that Jining always has lower dependence on foreign trade than Zibo, which was lower than 2\% for three consecutive years from 2013 to 2015 and it was not until 2016 that it reached 8\%. It suggests to a certain extent that the city's degree of opening to the outside world needs urgent improvement. 


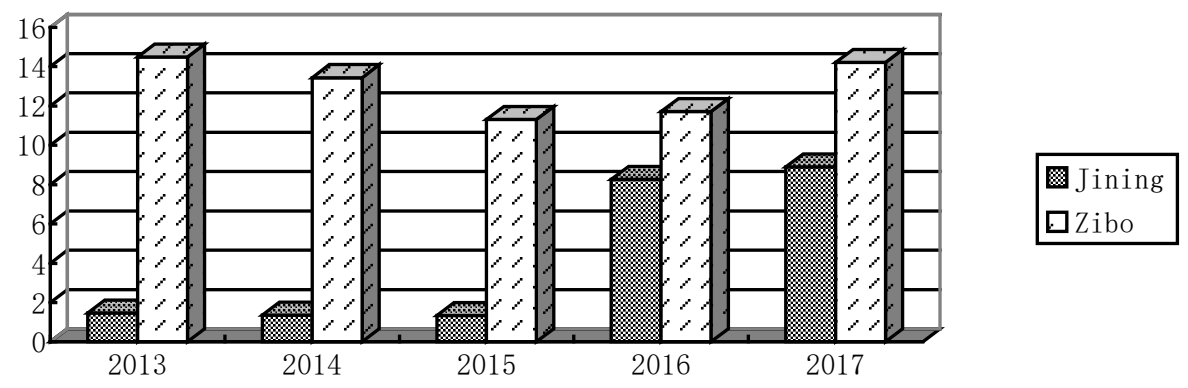

Figure 6 Comparison of foreign trade dependence (\%) between Jining and Zibo during 2013-2017

Source: Compilation and calculation based on data from Shandong Statistical Information Network

\subsection{Effect of Qi Culture on Economic Development of Eastern Shandong-A Case Study of Zibo}

\subsubsection{Zibo City's Economic Development Status under the Effect of Qi Culture}

Zibo, the birthplace of Qi culture, is one of the "Top 30 Cities in Comprehensive Strength in China" and is also a city in the Shandong Peninsula Economic Open Zone approved by the State Council. Zibo (Linzi District) was the largest city in the world from Spring and Autumn Period to the early Western Han Dynasty. Zibo City has a total area of 5965 square kilometers. At the end of 2017, the total population reached 4,331,300, of which 1.5721 million were rural and 2.7592 million were urban. In 2017, the total GDP of Zibo was 478.132 billion yuan, with a per capita GDP of 101,781 yuan and ranking fifth among the province's 16 cities.

\subsubsection{Zibo City has rapid development of urbanization}

Vigorously promoting new-type urbanization is an important starting point for Zibo City's mode transformation and structural adjustment, an important engine for maintaining stable and rapid economic development, which is also the only route to coordinate urban and rural development. Figure 2 shows that since 2006, Zibo City has higher proportion of urban population than Jining, which suggests its fast urbanization development to a certain extent. Seen from the whole province, in 2017, Zibo's urbanization rate reached 70.26\%, ranking third in the province behind Qingdao and Jinan.

\subsubsection{The coordinated development of urbanization, industrialization and non-agriculturalization in Zibo City}

With the continuous acceleration of industrialization process and the rapid development of service industry, Zibo City shows significant changes in non-agriculturalization characteristics. Since 2011, the proportion of the added value of the primary industry in Zibo has maintained between $3.1 \%$ and 3.5\%, while that of the secondary industry has dropped from $60.7 \%$ in 2011 to $52.1 \%$ in 2017 . That of tertiary industry increased from $35.8 \%$ to $44.8 \%$ over the same period, with the industrial structure increasingly optimized. According to statistics from the Statistics Bureau of Zibo City, at the end of 2018, the city's urban employment increased by 129,100, a year-on-year increase of $23.48 \%$. The new employment was mainly in the tertiary industry, and the demand for employees in this industry accounted for $49.6 \%$, which is an important sign of a higher level of urbanization.

\subsubsection{Zibo City's export-oriented economy enjoys a good momentum of development}

In 2018, the total import and export volume of Zibo City was 95.24 billion yuan, ranking the sixth in the province, of which 41.85 billion yuan were derived from export and 53.39 billion yuan were derived from import. Zibo City actively implements "Several Measures to Promote Steady Growth of the Import and Export of the Whole City" and promotes the steady growth of import and 
export trade by providing interest subsidies on the import of bulk resource products and giving full subsidies to small and micro enterprises in export credit insurance. By further optimizing import and export structure, increasing the proportion of exports of mechanical and electrical, high-tech and service trade, and expanding the import of advanced technology, major equipment, key parts and components and strategic materials, Zibo greatly promotes the city's development of export-oriented economy.

\section{Conclusion}

It can be seen from the above analysis that the economic development status of Zibo and Jining is quite similar to that of ancient Qi and Lu states. Qi culture advocates prosperity, openness, pragmaticism, rule of law, which is compatible and inclusive. Zibo City inherits the old customs of Qi state. Open and transformative, it has a tradition of relying on industry and commerce. Today, Zibo still has stronger economic development than Jining, thus revealing the far-reaching effect of culture on economy. To achieve coordinated economic development, Shandong Province must strive to carry forward the excellent traditions of Qi-Lu culture, while continuously absorbing and integrating advanced factors in other regional cultures, advancing with the times, and striving to shape new Qi-Lu culture with distinctive characteristics of the times. In this way, it can guide citizens to positive economic concept, standardize economic behavior, economic operation and economic order, and give play to the role of Qi-Lu culture in promoting Shandong's economic development.

\section{References}

[1] Enn Lun Yong. Uderstanding cultural diversity and economic prosperity in Europe: a literature review and proposal of a culture-economy framework. Asian Journal of German and European Studies,2019(5): 1-34

[2] David Hutchison. Culture sector contributes extra £7bn to economy. The Stage, 2016.

[3] He Huaihong. The cultural value motivation of China's economic development since the reform and opening up. Wuhan University Journal (Philosophy \& Social Science)2019(5): 43-49

[4] Lu Linkun. Exploration on the influence of Taiwanese culture on regional economic development. Journal of Fujian Radio \& TV University, 2019(5): 49-53.

[5] Tang Jin. Coupling and evaluation of economic - ecological - cultural system in the construction of beautiful countryside. Seeker, 2019(4): 82-188.

[6] Guo Yonghong. Local culture drives economic development. People's Tribune, 2018(9): 122-123.

[7] Zhang Jiangtao. The role of regional culture in regional economic development. Modern Communication,2018(23): 6-67.

[8] Mao Zhenpeng, Yang Yanting. The Realistic Significance of Qi Culture and Lu Culture in China's Economic and Social Development. Journal of the Party School of CPC Qingdao Municipal Committee and Qingdao Administrative Institute, 2011, (3): 121-124.

[9] Sun Haiyan. Discussion on the Development of Relationship between Qi-Lu Culture and Economy of Shandong Province. China Three Gorges Tribune, 2010, (1): 96-99.

[10] Sun Haiyan. Effect of Qi-Lu Culture on Shandong's Economy. Journal of Yangtze University, 2009, (4): 74-76.

[11] Wang Xiuzhi. The Far-reaching Impact of Qi-Lu Culture on Shandong. Theory Front, 2008, (13): 27-28.

[12] Long Shenfeng. Coordinated Development of Regional Economy in Shandong Province. Jinan: Qilu University of Technology, 2014.

[13] Sun Haiyun. Urbanization Approaches and Countermeasures of Jining City. Jinan: Shandong Agricultural University, 2005. 